\title{
13
}

\section{Preserving the Midwestern Barn}

\author{
Hemalata C. Dandekar and Eric Allen MacDonald
}

THE BIG RED, or white, barn is a readily recognized cultural icon, perhaps because many Americans share a relatively recent agrarian heritage and identify with the family farm it symbolizes. To many, the family farm and the traditional values associated with farm families have come to represent the antithesis of modern urbanism, which has often been blamed for many of the social problems confronting our nation. Agriculture, and agricultural structures, have shaped the image many Americans have of the Midwest. Picturesque barn scenes are featured on greeting cards, calendars, and posters, and farm architecture is even represented in children's toys (fig. 13.1). Agricultural settings frequently appear in television and magazine advertisements and are used to evoke a sense of security, stability, wholesomeness, or honesty.

Despite the romantic imagery and fondness which many Americans hold for barns, these structures are rapidly disappearing from the midwestern countryside. Some are being bulldozed, along with the rest of the farmstead, to make way for new housing developments, shopping malls, or office centers. Many more are sinking slowly into the earth as years of neglect and weather take their toll. New "subrural" landscapes are emerging as suburban-style residential and commercial development infiltrates rural lands and renders alien the existing traditional farm structures. The causes of this decline are varied and numerous, and the prognosis for stemming it doubtful. What is encouraging, however, is that more people now recognize that, as barns disappear, a valuable part of our heritage is lost (Carlson 1978; Dandekar and Bockstahler, 1990).

National and local preservation groups, in a shift from focusing primarily on "high-style" or monumental buildings, are beginning to identify barns and other agrarian structures as cultural resources worth saving (Fedelchak and Wood 1988; Stokes et al. 1989). The preservation of vernacular buildings and historic rural landscapes recently has become a major thrust of the federal government's National Register of Historic Places program. The National Trust for Historic Preservation launched a Rural Conservation Project in 1979, and in 1987 co-sponsored with the magazine Successful Farming a "Barn Again!" program to encourage farmers 


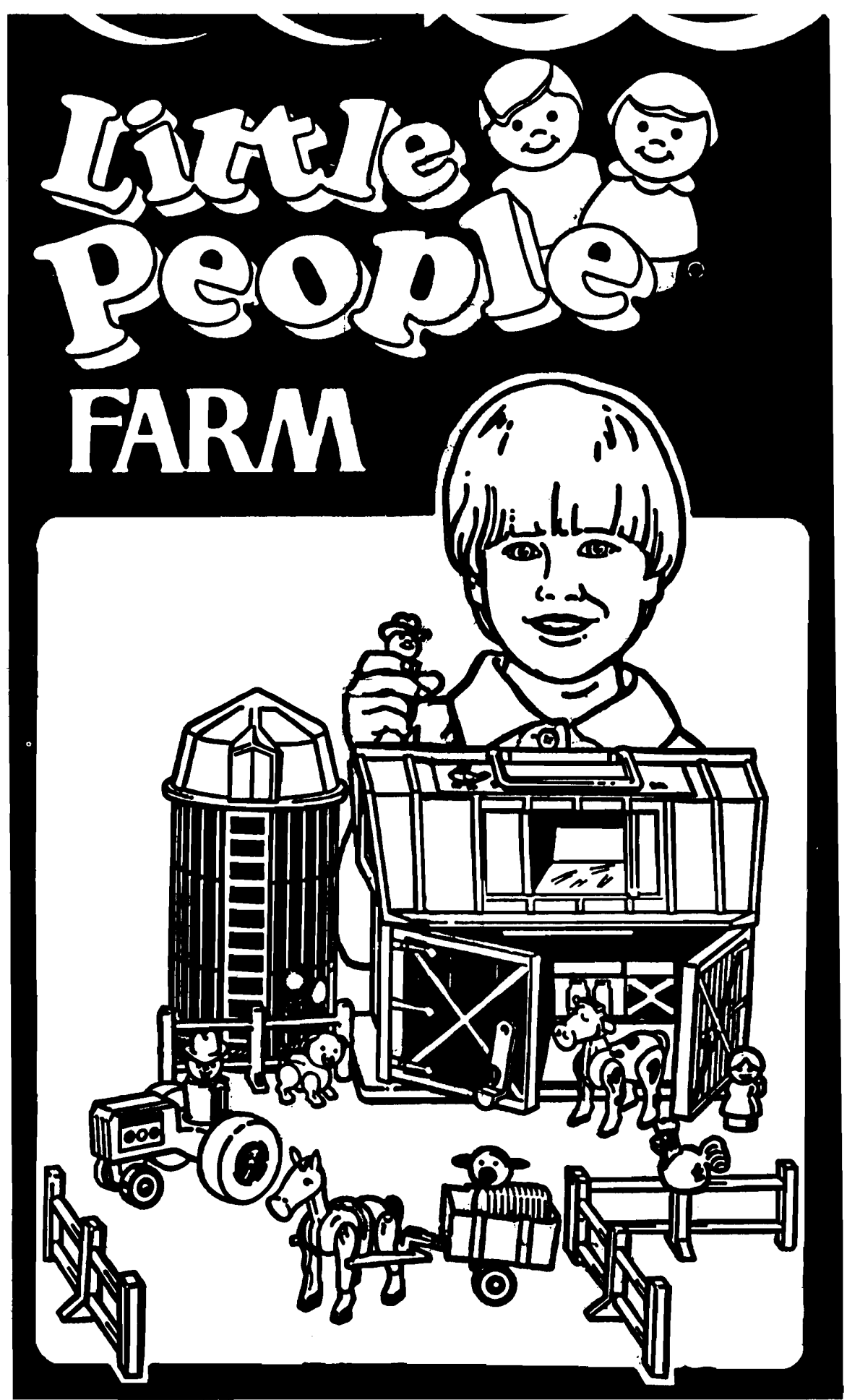

Fig. 13.1. Fisher Price's "Little People Farm" is found in many American homes, urban or rural. Prominently featured is the big red barn and silo. This toy may give young minds a lasting impression of farm life as it was in 1940s. 
to rehabilitate their barns (Humstone 1988). The Barn Again! program continues to receive considerable media attention across the country. In addition, rural conservation efforts in several states are specifically addressing the problem of preserving barns.

Preserving the midwestern barn is a daunting task. Unfortunately, the responsibility falls primarily on farmers, individuals engaged in an industry widely recognized as being under duress (Ball and Beatty 1986; Davidson 1986; Brodner 1987). Barn owners, even if they value their barns and are inclined to preserve them, face many challenges of a technical and institutional nature. If their dilemma is to be eased, strategies for barn preservation and reuse must be designed and implemented. Preservation options must be cost effective. Such preservation strategies must address both the nature and quality of the barn as a material artifact and the larger system or context in which the barn exists.

A strictly traditional preservation approach that seeks to create a museum by freezing the structure in a selected time frame will not be widely successful. Modifications that allow barns to shelter nontraditional farming activities, but which make the structures commercially viable, must be accepted. Strategies should attempt to save barns and any cluster of surrounding agricultural buildings by exploiting the social and economic systems at work in the community and region.

Preservation action at the scale of the individual barn could be encouraged by making changes in local and regional regulations and by providing technical assistance to barn owners. In developing effective and appropriate barn preservation strategies for a specific region, the following three questions might be answered: Why are barns being lost? Why should barns be preserved? What are the evaluation and identification issues in preserving barns?

\section{Why Are Barns Being Lost?}

Across the Midwest, barns and other traditional farm structures are vanishing from the landscape (fig. 13.2). Asking why is a crucial first step toward identifying potential strategies for stemming the decline. The many factors that contribute to the big barn's disappearance in the Midwest can be organized under three trends: (1) urbanization; (2) innovations in farm technology; and (3) the spread of corporate farming and agribusiness.

Near growing cities, many barns are lost to urban sprawl. The most noticeable effect of this trend is a zone frequently called the urban fringe where agricultural land is in transition to low-density residential and commercial strip uses. The image of a picturesque farmstead being bulldozed to make way for more suburban sprawl raises the popular conscience and often spurs rural preservation efforts. The underlying destructive nature of urbanization often is less overt than that of the bulldozer, but more insidious in the extent of its impact on barns.

A host of problems accompany the process of urbanization. The characteristics of good quality farmland-land that is flat, well-drained, and easily accessiblealso make it attractive for urban development. As a result, much of the farmland lost to urbanization is of above-average quality. Barns are allowed to decay on farmland that has been removed from production for land speculation purposes. 


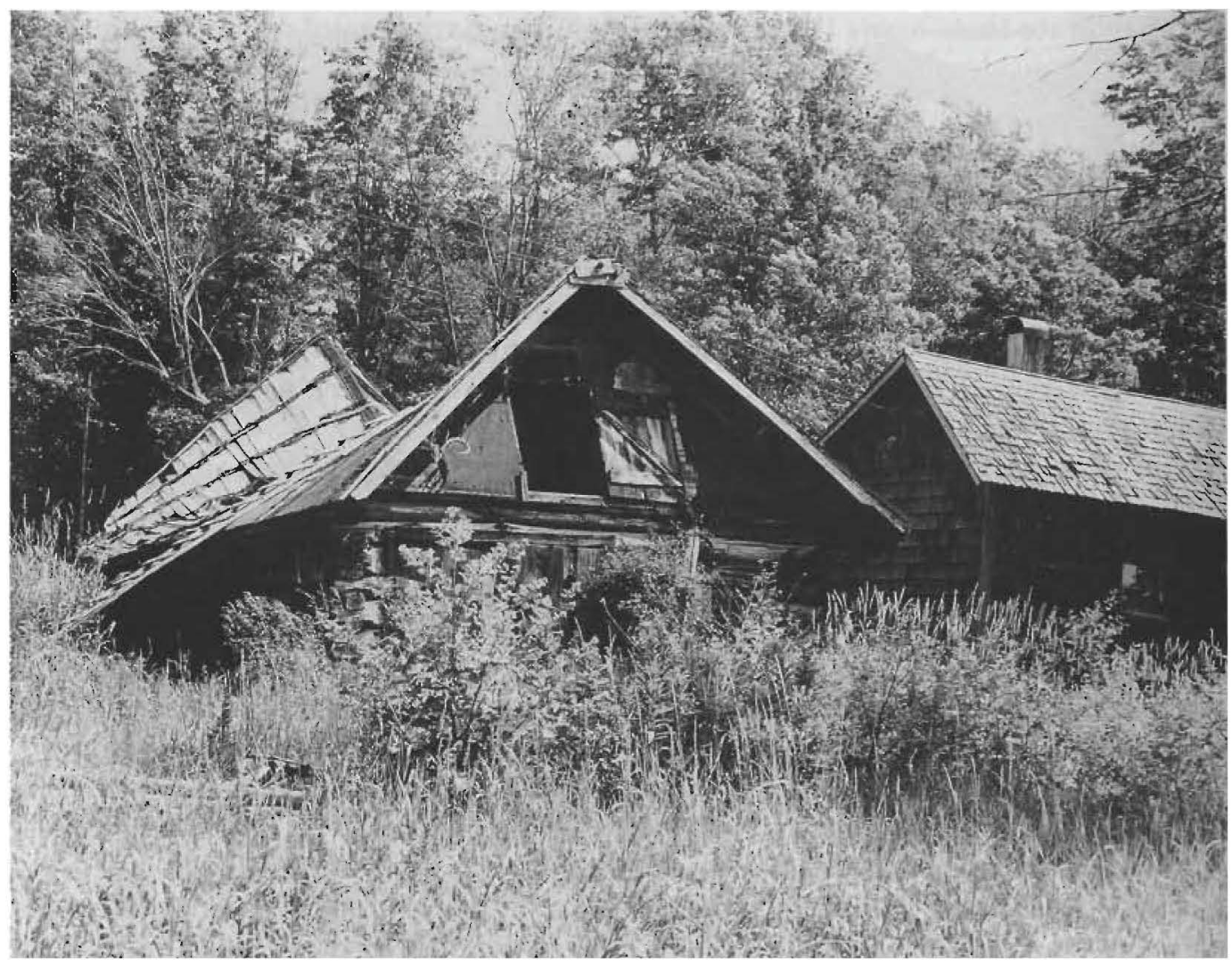

Fig. 13.2. Barns on an abandoned Finnish farm outside Ontonagon, Michigan

Tax policies that set rates on property according to its "highest use" encourage the idling of farmland and its sale to developers and land speculators. Increases in real estate taxes, which occur as a result of the maintenance or rehabilitation of barns, further encourage neglect.

A related problem, termed "the impermanence syndrome," occurs when farmers see agricultural land in their community being developed for other uses and come to believe that their land will inevitably be developed, too. This expectation may lead farmers to defer long-term improvements or maintenance of capital facilities such as buildings (Lockeretz 1989; Berry 1978).

Although the decline of barns in the urban fringe is of great concern, the number of barns lost in "suburbanizing" areas is much lower than the number being lost in more remote rural areas. Across the Midwest, more barns are disappearing due to neglect than to bulldozers. Two interrelated trends contribute to this loss: changes in agricultural technology and changes in the agricultural economy that have redefined the scale and scope of farming in the Midwest (fig. 13.3).

Technological changes have historically influenced almost every aspect of farming, including how barns are used. Most barns in the Midwest were built in the nineteenth or early twentieth century, before the widespread mechanization and specialization of agriculture. When these buildings were built, many farms 


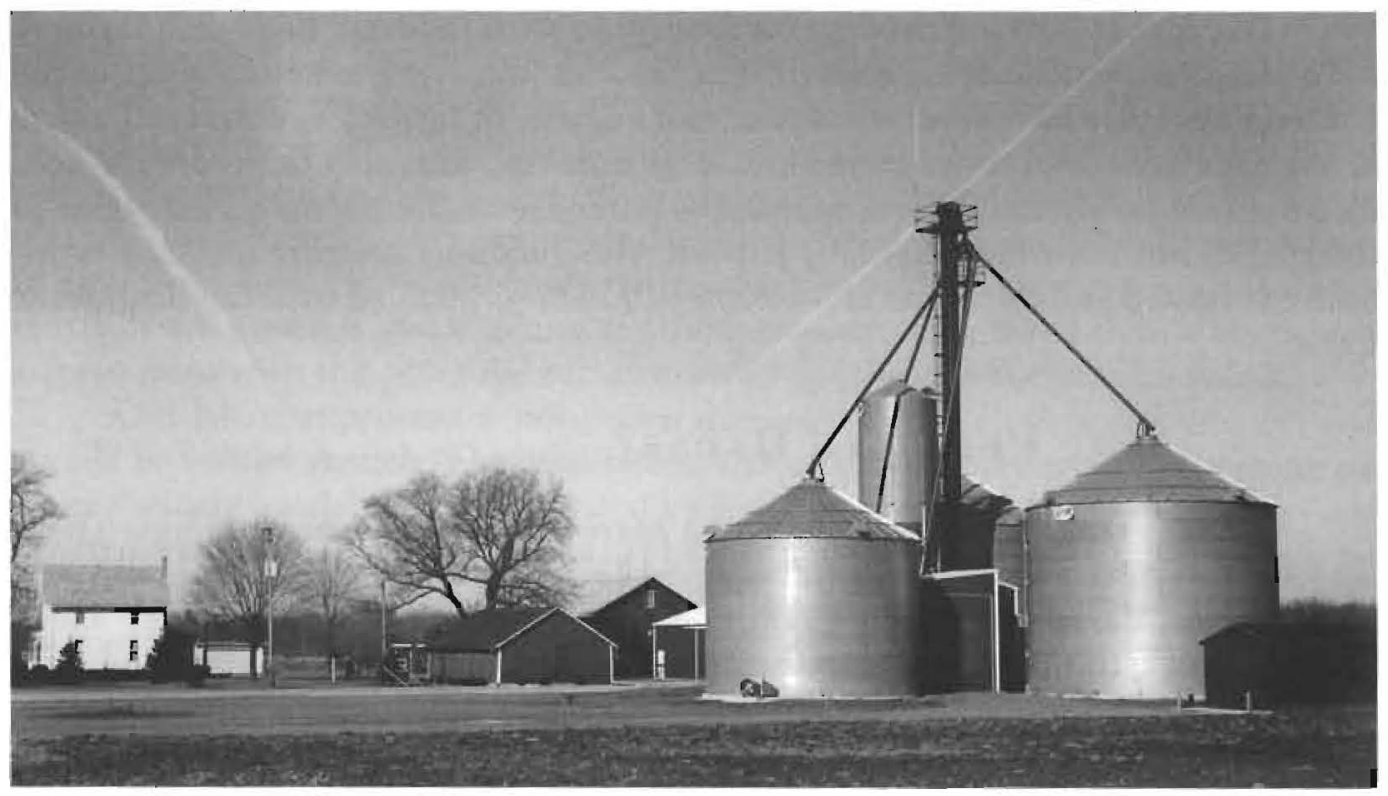

Fig. 13.3. Giant metal storage containers dominate this farmstead and its traditional barns in southeastern Michigan.

depended primarily upon human and animal power and raised a variety of crops and livestock. As farming practices changed and new technologies were introduced, the big barns were modified to meet new needs. (See chapter 8 for a discussion of this process.)

In almost every farm enterprise, the increased use of heavy machinery has diminished the usefulness of older buildings. Door openings in traditional barns are often too small for the new, larger equipment, and the heavy post-and-beam structure of many barns is too difficult to maneuver around. Old structures may have difficulty meeting sanitation and safety requirements for livestock operations, and electrical and plumbing systems are often inadequate. The huge round bales produced by modern mechanical hay balers have rendered the haylofts of many old barns useless, since these bales can be left outside through the winter, or stored in open shelters. Many older barns were built for specific functions that are no longer needed today, such as sheltering horses. The trend toward specialized production and monocropping has resulted in farms on which few animals are reared and need shelter (Dandekar and Schoof 1988).

To compound these problems, the big barn often becomes a liability to farmers because property taxes are levied on it, even if unused. Thus, old barns are viewed by many farmers as unsuitable for modern agricultural practices and as a financial liability. They believe that rehabilitation of old structures for modern uses is usually not possible, and when it is, it is more complicated and more expensive than building anew. The lending policies of financial institutions also frequently reflect this idea, even though numerous barn rehabilitation projects have proven successful and economical (Humstone 1988; Johnson 1988). 
The higher costs of production associated with modern, high-tech farming have affected the scale of agriculture. For decades, the average size of farms in the United States has increased, while the total number of farms has decreased. Small farmsteads have been consolidated into large holdings, as family farms are replaced by corporate farms. Large farm operations purchase smaller farms for the value of their land, not their buildings. As a result, the buildings are razed, or the farmhouse is rented and the barns and other outbuildings allowed to decay (Dandekar 1989).

\section{Why Preserve Barns?}

Many reasons exist for conserving barns and older farm buildings. These reasons encompass individual psychological factors and social, cultural, and economic needs. Barns are tangible reminders of our cultural heritage; they speak about the past; they contribute to the aesthetic quality of the local landscape, and, in some cases, promote local tourism; and old barns are not terminally obsolete, but are significant nonrenewable resources which can be useful and productive when put to a variety of other uses.

Barns are visible reminders of our agrarian heritage. At the personal level, the structures on a farmstead often hold a special meaning for family members whose ancestors built and used them. Barns, and other farm buildings, can be tangible links to a family's past. Barns also may be important in reinforcing a rural community's cultural identity and local sense of place. Perhaps one of their most important contributions is in providing a tangible connection with a past lifestyle, one to which popular culture has given a patina of nostalgia and embodied with nobility and virtue. Preservation of old barns and other traditional structures and landscape features provides a community with a sense of continuity. Many such structures are community landmarks. Such is the case with a polygonal barn in Hastings, Michigan. In interviews authors of this chapter conducted with area residents, this large and unusual barn surfaced as a focal point of their cognitive maps. Significant barns often become such mental landmarks for succeeding generations.

Barns and rural landscapes should be preserved for what we can learn from them. As the essays in this book demonstrate, barns can communicate information about past cultures, technologies, values, and ways of life. Through their form, their geographic distribution, and their relationship with the land and other man-made structures, barns reveal information about the social and economic development of rural regions, communities, and the people who built them.

We know we can learn from the past. We also should recognize that the past can tell us much about the future. For example, the study of historic vernacular environments can reveal how people solved design problems by modifying the environment. The study of vernacular building processes has the potential to influence the way we shape environments today, to help us create more humane, culturally meaningful places for people to live (Hubka 1986; Domer 1989, 56). The buildings and landscapes of the past represent a wealth of design precedents and a source of ideas for the future. 
There is an important utilitarian reason for conserving old barns. Many offer large open spaces that can be efficiently exploited for new farm uses such as livestock shelter, repair shops, or storage. For farmers, the rehabilitation of older farm structures is a viable alternative to new construction. Rehabilitation can be less expensive and require less capital outlay since it can be done in stages ("pay as you go"), and barn owners can often do much of the necessary work themselves. In localities where continued farm use is not a viable alternative, barns can be successfully adapted for a wide range of other purposes. Old barns should be viewed as resources with the potential for increased economic and utilitarian value.

Old barns represent a nonrenewable material and cultural resource, and should be valued as such. The quality and size of timber used to build them are no longer widely available. The technical knowledge and skills needed to design and construct them are disappearing as old barn builders die and young builders are no longer trained in the art. Conserving existing barns and returning them to productive use therefore makes good environmental sense.

\section{Some Problems of Identifing and Evaluating BARNS}

Not long ago, preservation activity was viewed as obstructionist, the work of a few fanatics aiming to impede growth and progress. However, citizens and public officials have increasingly come to appreciate the role historic places play in enhancing the quality of life in their communities. Preservation is coming to be recognized as a way to manage change in human environments (Stovel 1987; Fitch 1990). For preservation to be successful in the rural Midwest, it must be reconceptualized, largely because much of the midwestern environment is a vernacular environment.

The notion that preservation only involves artifacts associated with major events, persons, or monumental architecture leads many people to believe that more humble artifacts are not really "historic" or "significant," and that they are therefore not worthy of preservation. It is clear that focusing preservation efforts on "significant" artifacts, as defined by these criteria, leaves out many vernacular artifacts, including most barns. Yet, vernacular buildings, including barns, are culturally significant. A more holistic approach to preservation is needed which allows for multiple definitions of significance and for enough flexibility to preserve the nature or essence of the artifact.

Most vernacular buildings are utilitarian in nature, built by ordinary people using local customs, knowledge, and materials (Heath 1988). The typical midwestern barn is no exception. Most barns have been constantly added to, altered, rebuilt, and remodeled throughout their history. They are the products of many individuals, generations, ideas, and social and economic changes. The sense of evolution communicated through vernacular environments is what makes them meaningful. Their significance is often local, highly personalized, and, in many cases, subconscious. The aesthetic criteria for the conservation of folk and vernacular buildings 
and landscapes should reflect the nature of vernacular artifacts (Stovel 1987). The preservation criteria should treat them as dynamic, utilitarian artifacts meant to serve a purpose and to adapt and change as circumstances require.

In some cases it may be entirely appropriate to preserve a vernacular building in a "pure" state, for example, in dealing with an exceptionally rare, intact vernacular artifact for pedagogic value, or in maintaining a certain visual character in an area for economic or social reasons. To achieve wide-scale preservation, the strategy must be sufficiently flexible and dynamic, and it must embrace change.

\section{Alternative Approaches for Preserving BARNS}

In considering which strategies would work to preserve the barns in a particular region, aesthetic and pedagogic concerns must be balanced with utilitarian concerns such as cost and efficiency.

Preservation at the micro-scale level, i.e., that of individual barns and barn owners, can be encouraged through technical assistance. Even with incentives, preservation will not happen if barn owners lack the technical expertise needed to rehabilitate and maintain their buildings. Conversely, providing technical assistance without offering economic incentives or protection through zoning and other measures, will not encourage owners to invest in their buildings.

An ideal way to preserve large barns is to preserve the economic and social system-small-scale, diversified, family farming - that produced and depended upon them. Since this system, with few exceptions, no longer exists today, the buildings it needed, such as the big barns, have become redundant. Ideally, the productive unit, the small-scale, diversified, family farm, should be saved. Barn preservation would thus be a natural outgrowth of building strong farm communities. This solution would preserve the dynamic utilitarian quality of barns, as well as the larger, rural cultural system of which they are a part.

A large farm is not always more efficient than a small one. Small farms also may have substantial ecological advantages over large ones, partly because of the more intensive care the small farmer gives his or her land.

If a regional or local planning strategy is oriented toward preserving the small-scale, diversified, family farm, older barns would be maintained because they would still be needed for functions similar to those for which they were built generations ago. This approach could enhance the conservation potential of other buildings and landscape elements such as hedge rows and windbreaks. Nationally, some efforts to establish green belts around urban areas have promoted the concept of family farming. Establishing urban-rural linkages that enable the family farmer to sell products direct to retailers is part of this approach (Dandekar 1989). Such an arrangement could make farming on smaller land holdings more profitable (Lockeretz 1989).

Some well-known techniques useful in preserving old barns and farmland include performance zoning (Porter, Phillips and Lassar 1989; Stokes et al. 1989), cluster development and open space zoning (Yaro et al. 1988; Stokes et al. 1989), 
local historic district and design review ordinances (Stokes and Getty 1979; Stokes et al. 1989; McClelland et al. 1990; Hall 1991), recognition programs (Humstone 1988; Poll 1990), tax policies (Stokes and Getty 1979; Miner 1980; Stokes et al. 1989), minimum-lot-size subdivision rules (large lot zoning) (Stokes and Getty 1979; Miner 1980; Stokes et al. 1989), agricultural zoning (Toner 1984; American Farmland Trust 1987; Stokes et al. 1989), agricultural districts (Miner 1980; American Farmland Trust 1987; Stokes et al. 1989), right-to-farm laws (Stokes et al. 1989), conservation/preservation easements (Watson 1982; Diehl and Barrett 1988; Stokes et al. 1989; Ward and Benfield 1989), and purchase or transfer of development rights (Stokes and Getty 1979; Miner 1980; American Farmland Trust 1987; Stokes et al. 1989). Implementation may depend on the existence of state-level enabling statutes, so the situation necessarily varies from state to state (Bushwick and Hiemstra 1987). The design and implementation of measures such as these should be approached with caution in order to avoid unanticipated, negative side effects. For example, rural residents may strongly oppose land-use regulations if they are difficult to comply with, are implemented capriciously, or do not reflect the community's values. Local opposition or poor design of any regulatory or incentive device may actually hinder the preservation effort in the long run.

One effective barn-preservation strategy is to find ways to extend the viability of a traditional barn on an existing farm, or to make it useful in a farmrelated enterprise. Adaptation for new uses is in keeping with the historical utilization of barns. Most earlier barn adaptations were relatively small, incremental changes, usually to meet new requirements of "modernizing" the farm operation. For example, when farmers in Michigan turned from wheat to dairy production, they needed to modify the basement areas of the barn to house animals, as well as to build silos to feed the cows year-round. Change also occurs as a result of evolution in building technology, for example, the shift from heavy timber to increasingly lighter-frame structures discussed in chapter 8. Innovations in farming technology include the construction of silos and their placement relative to the barn (Dandekar and Savitski 1989). The displacement of horses by tractors required changes in the size of door openings and more navigable ramps and other access to the barn (for other changes see chapters 5 and 11).

Barns also changed as a result of regulatory legislation intended to improve the quality and safety of farm production. For example, sanitation considerations on dairy farms resulted in mandated standards for lighting, ventilation, and requirements that specified elements of the processing plant be constructed of concrete and steel. A separate milk house had to be built and was often attached to one of the external walls of the barn.

In this same vein, current adaptations can be experimented with in the effort to preserve a barn. Several examples of how big barns have been adapted for productive use in small-scale, diversified agriculture, or in large-scale agribusiness, are provided in the Barn Again! booklet (Humstone 1988) and in a research bulletin issued by North Dakota State University's extension office (Johnson 1988). Johnson (1988) provides some excellent examples of ways in which old barns of various configurations can be successfully and economically rehabilitated for farm uses. These include swine farrow and nursery, cattle feeding, machinery repair, 
grain storage, seed cleaning and storage, dairy calf housing, ewe housing, lambing, and poultry. Agriculture-related uses, such as horse stables and training spaces, farm produce markets, and cottage industries such as cheese factories and spinning or weaving shops, also have been successfully housed in traditional barns.

Use of large barns to shelter activities that are far removed from original functions is another crucial preservation strategy. In rapidly urbanizing areas, continuing a farm or farm-related operation may not be viable, yet the large volume and usable area that a barn encloses offers excellent shelter for a number of commercial and social activities. In continental Europe and the United Kingdom, where protecting historically significant structures is a tradition, there are many successful examples of conversions of farm complexes to art galleries, studios, residences, showrooms, and production facilities.

U.S. barn conversions are not as widespread, yet have been more far ranging in terms of function. Barns have been converted into reuse as churches, community theaters, farm museums, local museums, commercial markets, farm produce markets, storage facilities, light industrial production, workshops, boutiques, stores, professional office space, restaurants, artist studios, art galleries, health clubs, and sports facilities (fig. 13.4).

Nevertheless, the further a new usage is from the original barn function of commodity storage and animal shelter, the more complicated the technical issues related to rehabilitation. Conversion to residential uses may be the most problematic, because of stringent requirements for health and safety. Furthermore, a barn-to-house conversion can make a dramatic impact on the building's exterior. Barns usually have few openings other than the big doors, and most homeowners want lots of windows. Other exterior features of a house, such as chimneys, can drastically alter the appearance of a barn. And, while heavy timber may be aestheti-

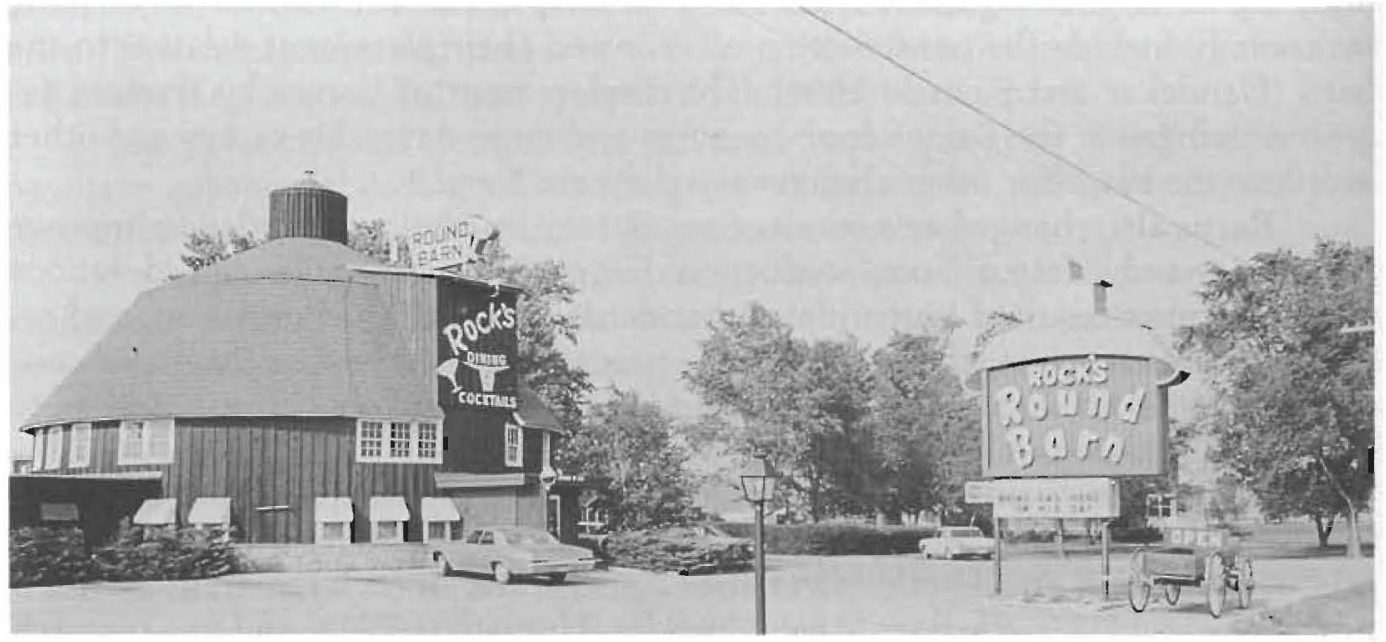

Fig. 13.4. Unique agricultural structures such as this round barn in Spring Green, Wisconsin, frequently become well-known local landmarks and have the potential to become symbols of community pride and to attract tourists.

Photo: I. Vogeler 
cally appealing, it presents problems in concealing wiring or plumbing, and in installing insulation. Barns are large, making for large living spaces, but they are expensive and certainly not for everyone.

\section{Structural and Architectural Design CONSIDERATIONS}

The chronological, structural, and architectural evolution of the midwestern barn has implications for the most suitable adaptive reuse. The evolving structure and spatial organization of midwestern barns reflected cultural, economic, and technological transformations in the agriculture of the Midwest. An understanding of the evolution of barn types is useful in identifying the most significant structural and aesthetic aspects of a particular barn. This enables the designer to both preserve and exploit these characteristics to their fullest advantage when designing reuse.

The structure of a barn may be its most important characteristic. The structural frame may largely determine new uses of a barn. When contemplating reuse possibilities for old barns, a classification of their structure is useful. The Michigan Farm Project Phase II research team recently reviewed extension bulletins and publications of the agricultural experiment stations of the midwestern states, and the Canadian Province of Ontario, to identify the structure types that were being promoted for barns during the period 1880 to 1940 . This search produced a barn structure typology which reveals the spatial potential of six major types of structures (fig. 13.5). Over time, the volume of space enclosed under the roof became increasingly unobstructed by structural members (see chapter 5 for a detailed discussion). This increasing openness was a result of changes in the nature and quality of available construction materials, particularly wood, evolving support technologies and designs for trusses and ribs, and demands for more open unobstructed space for mechanical reasons (see chapter 11).

Heavy timber barns may present the greatest challenge for reuse. The bulky structural members often get in the way of large modern machinery or equipment, reduce the clear headroom available if intermediate floors are installed, and make the space less usable for storage. Modifying the structure can be difficult because of the weight and thickness of the posts and beams. Modification needs to be done in consultation with a structural engineer and with appropriately large construction machinery at hand. Modifications to the frame must be designed so that the integrity of the structure is not threatened. However, there is great reward which comes with successful conversion. The structure of a heavy timber-framed barn is often its most distinguishable and remarkable feature. It is very expensive to replicate and the large timbers used in the old construction often are no longer available. The heavy timber frame can be a great aesthetic asset when barns are adapted for reuse in nonfarm functions such as retailing. Whenever possible, a reuse design should keep intact the major structure of the barn.

Lighter-frame structures are more easily adapted for farm use. However, 


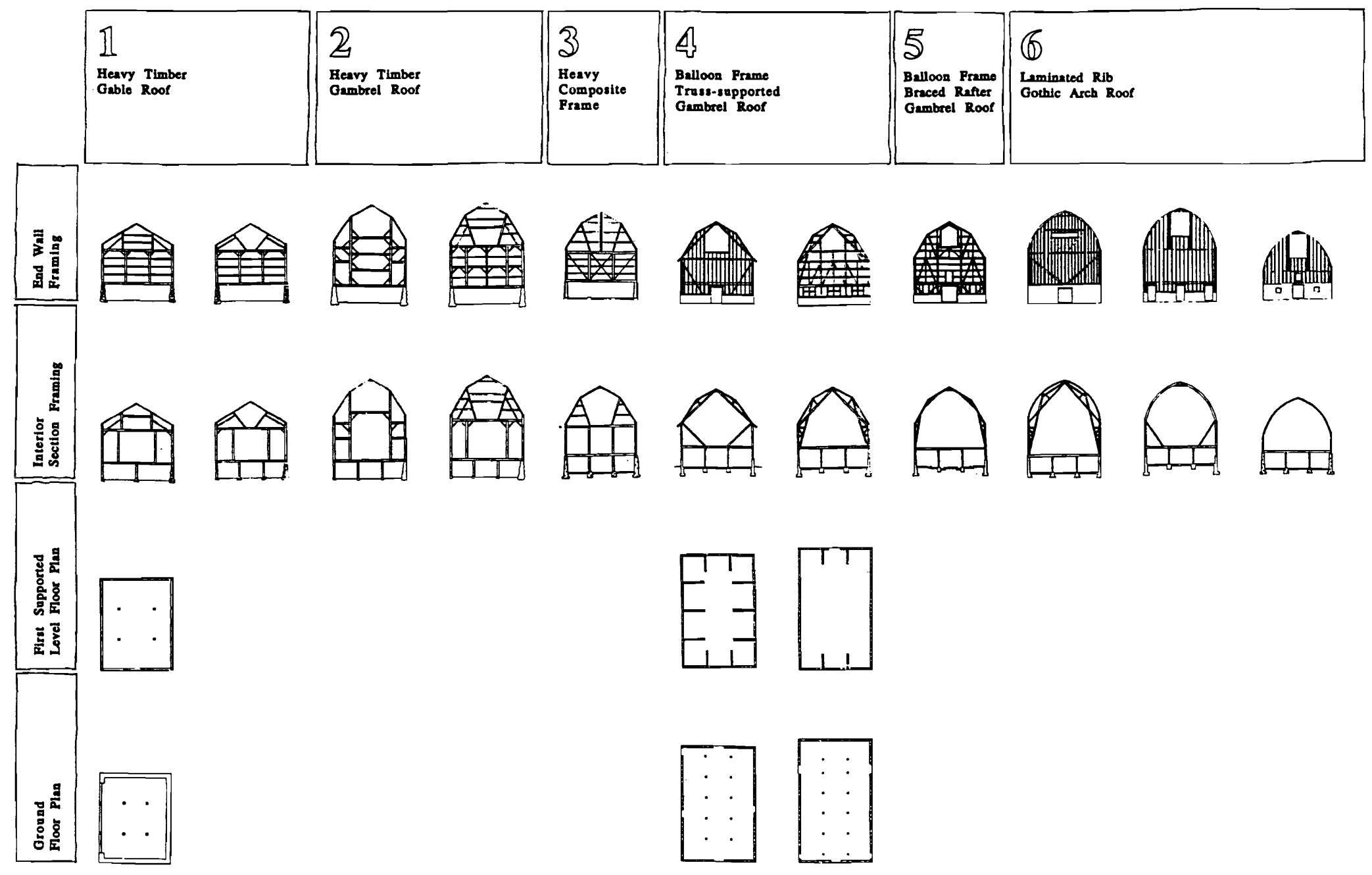

Fig. 13.5. The structure prototypes of the midwestern barn, developed from agricultural extension bulletins, illustrate the nature of the spaces available for reuse in different types of barns. The chronological development is of increasingly open plans and lighter frames. 
they have their own problems. Making significant additions to such buildings can be more challenging than to heavy timber ones. On these barns, the structure is often more susceptible to localized failure, and since the complete shell provides structural stability, such failure can quickly lead to the collapse of the entire building.

Scholars of material culture have developed typologies of barns based not just on form, but also on the massing of the buildings, the size, style, and location of openings, construction materials and methods, and minor decorative features (see chapter 1). The texture of the external skin of the barn, the massing of the barn form, the fenestration, door locations and size, and the ornamented details and joints provide the barn with a specific identity. For these reasons, in adaptive reuse, it may be important to maintain the visual appearance of barns as much as possible. Structural changes may have little effect on the visual presentation of the building, yet make all the difference in making the building useful again.

The design elements that give a barn its aesthetic appeal need to be understood and treated with sensitivity. Barn siting and relationship to surrounding landscape and ancillary structures, such as earthen bank or ramp, silo, sheds, milk house, farmhouse, and barnyard should be considered. Other issues concern barn volume and roof line and what can compatibly fit with the rectangular gable structure, with the roof lines of the gambrel or arch, with round or banked barns, and those with cantilevered lofts of various configurations. There, too, are issues of what kinds of modifications different structures, such as heavy timber, light wood trusses, and laminated beams and rafters, will accommodate. The nature and appearance of the materials-wood, stone, metal, or concrete-also must be respected. Decorative features such as cupolas, weather vanes, lightning rods, and dormers must be considered, as must painted decorations and the size and shape of ventilators and louvers. Types of windows and doors, their placement, number, and size may be significant. Finally, the existing condition of the building, its maintenance, the evidence of current and past use, and its evolution are all factors to be reviewed in the design process.

The location of the barns and the category of reuse (figs. 13.6 and 13.7) are additional factors that need to be addressed. When human habitation is involved, especially in urbanized areas, increasingly stringent building codes and zoning restrictions may be encountered. Issues of insulating, fireproofing, and safe access have to be addressed. Design solutions must incorporate ways to preserve essential aesthetic attributes of the existing construction. Modification should involve appropriate materials and shapes. Heating and ventilation strategies for new usage must be designed. A rehabilitated and adapted barn needs to conform to the governing codes so that permission to occupy is obtained and the structure is rendered insurable. The more barn adaptation and reuse involves human occupation, the more stringent will be the technical standards to be met and the more expensive the cost of making these changes.

Figure 13.6 is a decision-tree diagram incorporating a range of functions that might be considered when developing an adaptive reuse strategy for barns in a region. A community might decide to have a multiple-pronged effort which would include saving some excellent barns in a more traditional preservation ef- 

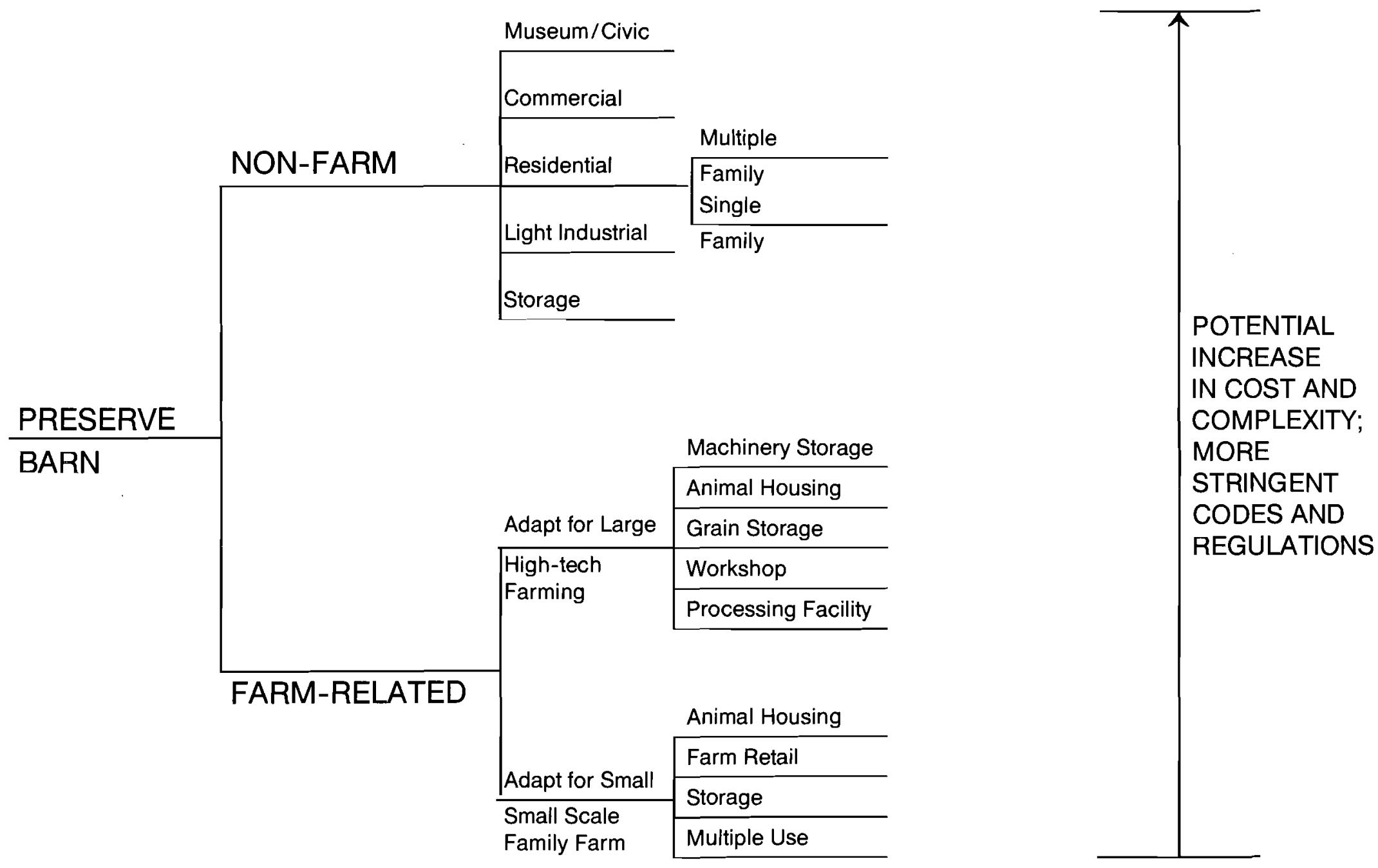

Fig. 13.6. Possible functions for barn reuse offer opportunities for an array of preservation strategies. 
fort. It also might create a scenic or historic district to protect the composite elements of a traditional farmscape and thus create an area where other kinds of economic development strategies become viable. For example, tourism and related services might flourish in such an area. In other areas, the strategy might encourage some tax abatement for adaptive reuse of traditional barns for modern farming or for commercial use in other functions.

\section{State and Local Legislation For Barn PRESERVATION}

Private rehabilitation of barns for continued use can be encouraged by legal frameworks at state and local levels. Specific measures depend upon the local context and the goals of the effort. For example, in urbanizing areas, the preservation strategy might focus on encouraging intensive farming of the remaining open land, and encouraging adaptation of barns for nonfarm, residential or commercial uses. In areas close to urban centers, direct-marketing of produce and promotion of tourism could be the components of such a strategy. In more remote rural areas, diversified family farming and rehabilitation for continued farm use might be the underlying objectives of a preservation strategy (fig. 13.7).

Ideally, a preservation effort is based on a comprehensive inventory of a community's resources, and an analysis of the threats that those resources face. Determining the state of small-scale family farming, inventorying land use and land ownership, and evaluating the quality and integrity of existing barns help identify problem areas and generate creative solutions. A survey of residents is useful so that preservation measures will reflect community goals and values. With this information in hand, specific preservation techniques can be tailored to both the nature of the barn resources in an area and the underlying cause of their decline.

\section{Where to Get Information and Assistance}

Several publications on barns and rural conservation provide general information about approaches and options for barn preservation. One important source of information for individuals and communities alike are State Historic Preservation Offices (SHPO). SHPOs carry out state-wide survey and preservation planning programs, review and prepare nominations to the National Register of Historic Places, and review applications for federal rehabilitation income tax credits.

The National Trust for Historic Preservation is another good source for preservation information. Its Barn Again! program may be of interest for those considering a farming use of their barns. The American Farmland Trust (AFT) is an organization devoted to preserving valuable but threatened farmland, and to promoting ecologically responsible farming techniques. AFT has completed several successful conservation projects in the Midwest. Many local land trusts or land conservancies make saving farmland a priority. Any local planning board or Cooperative Extension Office should be able to provide individuals with information on 


\begin{tabular}{|c|c|c|c|c|}
\hline STRATEGY & & PROMOTE N & N-FARM USE & \\
\hline & & & PROMOTE & FARM-RELATED USE \\
\hline CONTEXT & & $\begin{array}{l}\text { - Performance Zoning } \\
\text { - Historic District } \\
\text { w/Design Review } \\
\text { - Tax Relief (rehab) } \\
\text { - Preservation Ease- } \\
\text { ments } \\
\text { - TDR/PDR }\end{array}$ & $\begin{array}{l}\text { (small scale specialized } \\
\text { farming) } \\
\text { - Right to Farm } \\
\text { - Ag. Zoning } \\
\text { - Performance Zoning } \\
\text { - Cluster Development } \\
\text { - Historic District } \\
\text { - Tax Relief (for rehab } \\
\text { \& conservation) } \\
\text { - Conservation/Preser- } \\
\text { vation Easements } \\
\text { - PDR/TDR }\end{array}$ & $\begin{array}{l}\text { (diversified, moderate scale } \\
\text { family farming) } \\
\text { - Ag. Districts } \\
\text { - Tax Relief (Conservation } \\
\quad \text { \& rehab) } \\
\text { - Conservation Easements } \\
\text { - Greenbelt/tourism } \\
\text { - PDR/TDR } \\
\text { - Estate Planning }\end{array}$ \\
\hline & URBAN & SUBURBAN & $\begin{array}{c}\text { URBAN/RURAL } \\
\text { FRINGE }\end{array}$ & RURAL \\
\hline $\begin{array}{l}\text { POSSIBLE } \\
\text { USES }\end{array}$ & & $\begin{array}{l}\text { - Museum } \\
\text { - Residence } \\
\text { - Retail } \\
\text { - Service } \\
\text { - Community/Civic } \\
\text { - Office }\end{array}$ & $\begin{array}{l}\text { - Museum } \\
\text { - Residence } \\
\text { - Farm } \\
\text { - Farm Retail } \\
\text { - Farm Service } \\
\text { - Community/Civic }\end{array}$ & $\begin{array}{l}\text { - Storage } \\
\text { - Animals } \\
\text { - Workshop } \\
\text { - Processing Facility } \\
\text { - Farm Service }\end{array}$ \\
\hline
\end{tabular}

Fig. 13.7. Preservation strategies must integrate consideration of barn uses, context, tools and location. 
active local conservation programs. Some research and review of the existing literature on barns might be helpful to local barn-preservation efforts in the inventory, identification, and evaluation phases. Academic organizations that may be useful to communities wishing to learn more about barns include the Vernacular Architecture Forum (VAF) and Pioneer America Society (PAS). VAF publishes some of its annual conference papers in book form, as well as prepares a quarterly newsletter and bibliography. PAS publishes the quarterly journal, Material Culture and the proceedings of its annual conference in P.A.S.T.-Pioneer America Society Transactions.

\section{Conclusion}

Action at the local and state level to preserve the barns of the Midwest is crucial. The demise of traditional barns on the midwestern landscape need not be inevitable if local communities, hand-in-hand with state and national institutions and governments, take a positive and flexible stand for preservation. This chapter has provided some guidelines to help communities think about their specific barn resources and to contemplate alternative options for preservation. Issues that affect this consideration, such as the location of the barns, the nature of the surrounding economy, the functions that are viable within the barn structure, and the technical and financial issues of alternative barn uses, are critically important. The overarching message of this essay is that there is not one all-encompassing barn-preservation strategy that will be successful in all contexts, but rather that each individual and community must develop their own particular strategy.

We must start the preservation effort at any and every scale. We encourage a broad and flexible interpretation of preservation strategies rather than a more traditional, purist historic preservation approach, because we are convinced that this has more promise of obtaining the broad-based preservation effort needed if barns are to remain a tangible and viable element of our future landscape. 


\section{REFERENCES CITED}

American Farmland Trust. 1987. Planning and zoning for farmland protection: A community based approach. Washington: American Farmland Trust.

Ball, Heather, and Leland Beatty. 1986. Blowing away the family farmer. Nation 242(January 18): 44-46.

Berry, David. 1978. Effects of urbanization on agricultural activities. Growth and Change. 9(3): 2-8

Bleznick, Susan R. 1991. Midwestern vernacular: Charles Moore's TINOVA headquarters rephrases agrarian form. Inland Architect 35(4): 54-55.

Brodner, Steve. 1987. Plowed under. Progressive 51(May): 35-40.

Bushwick, Nancy, and Hal Hiemstra. 1987. How states are saving farmland. In Sustaining agriculture near cities, edited by William Lockeretz. Ankeny, Iowa: Soil and Water Conservation Society.

Carlson, Alvar W. 1978. Designating historic rural areas: A survey of northwestern Ohio barns. Landscape 22(3): 29-33.

Dandekar, Hemalata C. 1989. Michigan Farms Project: Phase I report. Lansing: Michigan Department of State, Bureau of History.

and Mary Bockstahler. 1990. The changing farmscape: A case study of German farmers in southeast Michigan. Michigan History 74(2): 42-47.

and John A. Savitski. 1989. The silo: A century of experimentation on the Michigan farm. Chronicle: The Quarterly Magazine of the Historical Society of Michigan 25(3): 2-5.

and Dan Schoof. 1988. Michigan farms and farm buildings: 150 years of transformation. Inland Architect 32(1): 22-27.

Davidson, Osha Gray. 1986. The rise of the rural ghetto. Nation 242(June 14): 820-21.

Diehl, J., and T. S. Barrett. 1988. The conservation easement handbook. San Francisco: Trust for Public Land.

Domer, Dennis. 1989. The old and the new of vernacular architecture: A review essay. Journal of Architectural Education 42(4): 45-46.

Fedelchak, Marilyn, and Byrd Wood. 1988. Protecting America's historic countryside. Washington: National Trust for Historic Preservation.

Fitch, James Marston. 1990. Historic preservation: Curatorial management of the built world. Charlottesville: Univ. Press of Virginia.

Hall, Donna. 1991. The role of local planning in the preservation of historic districts, Small Town 21(4): 12-24. 
Heath, Kingston W. 1988. Defining the nature of vernacular. Material Culture 20(2-3): 1-8.

Hubka, Thomas. 1986. Just folks designing: Vernacular designers and the generation of form. In Common places: Readings in American vernacular architecture, edited by Dell Upton and John Michael Vlach, 426-32. Athens: Univ. of Georgia Press.

Humstone, Mary. 1988. Barn again!: A guide to rehabilitation of older farm buildings. Washington: National Trust for Historic Preservation.

Johnson, Dexter W. 1988. Using old farm buildings: Agricultural research report No. 88-1. Fargo: North Dakota State Univ.

Lockeretz, William. 1989. Secondary effects on midwestern agriculture of metropolitan development and decreases in farmland. Land Economics 65(3): 205-16.

McClelland, Linda, J. T. Keller, G. P. Keller and R. Z. Melnick. 1990. Guidelines for evaluating and documenting rural historic landscapes. Washington: U.S. Department of the Interior, National Park Service.

Miner, Dallas D. 1980. The role of government in shaping the rural landscape. In New directions in rural preservation, ed. Robert Stipe, 83-89. Washington, D.C.: U.S. Dept. of the Interior.

Poll, Christine M. 1990. That darn barn. Preservation Forum 4(2): 4.

Porter, Douglas R., Patrick L. Phillips, and Terry J. Lassar. 1989. Flexible zoning: How it works. Washington: Urban Land Institute.

Stokes, Samuel, and Joe Getty. 1979. Rural conservation: Information sheet No. 19. Washington: National Trust for Historic Preservation.

Stokes, Samuel N., A. Elizabeth Watson, Genevieve P. Keller, and Timothy J. Keller. 1989. Saving America's countryside: A guide to rural conservation. Baltimore: Johns Hopkins Univ. Press.

Stovel, Herb. 1987. Managing change in vernacular settings. Association for Preseroation Technology Bulletin 19(3): 4-6.

Toner, William. 1984. Ag zoning gets serious. Planning (December): 20-24.

Ward, Justin R., and F. Kaid Benfield. 1989. Conservation easements: Prospects for sustainable agriculture. Virginia Environmental Law Journal 8(2): 271-92.

Watson, Elizabeth A. 1982. Establishing an easement program to protect historic, scenic, and natural resources: Information sheet No. 25. Washington: National Trust for Historic Preservation.

Yaro, Robert, R. G. Arendt, H. L. Dodson and E. A. Bradec. 1988. Dealing with change in the Connecticut River Valley: A design manual for conservation and development. Amherst: Univ. of Massachusetts, Center for Rural Massachusetts. 